\title{
Association between digital breast tomosynthesis and molecular subtypes of breast cancer
}

\author{
SIQING CAI, MIAOMIAO YAO, DONGLU CAI, JIANXIANG YAN, \\ MEILING HUANG, LISHENG YAN and HUIRONG HUANG
}

Department of Imaging, The Second Affiliated Hospital of Fujian Medical University, Quanzhou, Fujian 362001, P.R. China

Received February 11, 2018; Accepted November 29, 2018

DOI: $10.3892 / \mathrm{ol} .2019 .9918$

\begin{abstract}
In recent years, with increasing prevalence, particularly in young patients, breast cancer is considered to be one of the most common malignancies. The aim of the present study was to evaluate the clinical value of digital breast tomosynthesis (DBT) in diagnosing molecular subtypes of breast cancer. The present study retrospectively analyzed 134 cases of breast cancer with data regarding surgery, complete pathology and immunohistochemistry, which were collected at The Second Clinical College of Fujian Medical University (Quanzhou, China) between May 2013 and October 2014. The patients were divided into the four following molecular subtypes: Luminal A, luminal B, triple-negative and human epidermal growth factor receptor 2 (HER-2) overexpression, according to the expression of estrogen receptor, progesterone hormone receptor, HER-2 and Ki67. The association between clinical characteristics of each molecular subtype and characteristics of DBT were assessed. Calcification scores and lymph node size were the indicators that exhibited a significant difference following comparison between the four molecular subtypes. The subgroup analysis based on tumor size, calcification scores and lymph node size identified a significant difference in the distribution between patients with breast cancer with lymph node size of $\geq 1.5$ and $<1.5 \mathrm{~cm}$. The analysis also revealed that the molecular subtypes of breast cancer were significantly associated with variables of calcification scores and lymph node size. In conclusion, the diagnostic imaging features, including calcification score and lymph node size, determined using DBT could be used as assistant diagnostic markers of breast cancer molecular subtypes.
\end{abstract}

Correspondence to: Professor Siqing Cai, Department of Imaging, The Second Affiliated Hospital of Fujian Medical University, 34 North Zhongshan Road, Quanzhou, Fujian 362001, P.R. China E-mail: 1920455696@qq.com

Key words: digital breast three-dimensional tomosynthesis, breast cancer molecular subtype, calcification, lymph node, assistant diagnostic marker

\section{Introduction}

Breast cancer is the most commonly reported type of cancer worldwide and was the second leading cause of cancer-associated mortality in females (1). In recent years, with increasing prevalence, particularly in young patients, breast cancer is considered to be one of the most common malignancies (2). Breast cancer is often characterized as highly heterogeneous at the molecular level. On the basis of the expression of estrogen receptor (ER), progesterone receptor (PR), human epidermal growth factor receptor 2 (HER-2) and Ki67, four different molecular subtypes of breast cancer have been identified, including luminal A, luminal B, triple-negative and HER-2-overexpression. Luminal A is characterized as $\mathrm{ER}^{+}$and/or $\mathrm{PR}^{+}$, HER-2- cytokeratin 5/6 $(\mathrm{CK} 5 / 6)^{+/}$and Ki67 $<14 \%$. Luminal B is $\mathrm{ER}^{+}$and/or $\mathrm{PR}^{+}$, $\mathrm{CK} 5 / 6^{+/}$, HER-2 ${ }^{+}$and Ki67 $\geq 14 \%$. The HER-2-overexpression subtype is characterized as ER, $\mathrm{PR}^{-}, \mathrm{HER}-2^{+}$and $\mathrm{CK} 5 / 6^{+/}$. Lastly, triple-negative is ER', PR', HER-2- CK5/6 ${ }^{+}$and/or epidermal growth factor receptor $\left(\right.$ EGFR) ${ }^{+}(3-6)$. The clinical manifestations, treatment response and prognosis vary significantly between different molecular subtypes of breast cancer. Patients with breast cancer exhibit different manifestations in lymph node metastasis, histological grade and 5-year survival rate. Luminal A and luminal B tumors are well-differentiated and exhibit a low rate of metastasis $(7,8)$.

In clinical practice, it is understood that early recognition of breast cancer molecular subtypes is important for early specific treatment of breast cancer, and patients may benefit from earlier detection and improved therapeutic options with a prolonged survival time $(9,10)$. In recent years, with the development of imaging techniques, digital breast tomosynthesis (DBT) has had an impact on the diagnosis of breast diseases as images of breasts may be obtained from different angles in the process of scanning (11). These independent images can be rebuilt into a series of tomographic images with high resolution, which eliminates the problems caused by the tissue overlap and structural noise in a two-dimensional breast mammography $(12,13)$. Currently, DBT technology is developing in China. The majority of previous studies have focused on comparing the diagnostic efficacy of DBT with traditional digital mammography (14). Furthermore, DBT has been revealed to improve the characterization of magnetic resonance imaging results that are not identified by targeted 
breast ultrasound in preoperative breast cancer staging (15). However, there is a lack of evidence demonstrating an association between breast cancer molecular subtypes and imaging characteristics based on the DBT imaging technique. A previous study revealed that DBT has important influence and significance in the classification of breast imaging-reporting and data system (BI-RADS). The diagnostic sensitivity increased from $60 \%$ with traditional digital mammography to $82.9 \%$ with DBT and the specificity of the two techniques used together was $93.2 \%$ (16). Primary indicators for BI-RADS classification include tumor margin, surrounding bright ring of tumor, vascular images and calcification foci, lymph node size, and associations with surrounding glandular tissue (17-19), and identification of these indicators is improved in a tomographic image (20).

On the basis of previous studies, it was hypothesized that characteristics of DBT imaging could be used to assist the diagnosis of breast cancer molecular subtypes. The use of digital imaging to diagnose and authenticate molecular subtypes of breast cancer is of great interest in this field. The aim of the present study was to investigate the characteristics of each molecular subtype of breast cancer based on DBT. In addition, the associations between imaging features of DBT and molecular subtypes of breast cancer were evaluated for the accurate diagnosis of tumor features, with the aim to provide an accurate treatment strategy for clinical use.

\section{Patients and methods}

Patients. Complete pathology and immunohistochemistry data were collected from 134 female patients with breast cancer with a mean age of 46.5 years (range, 26-81 years) who had undergone surgery at The Second Clinical College of Fujian Medical University (Quanzhou, China) between May 2012 and October 2014. The patients were divided into the four following groups depending on the molecular subtype of breast cancer: Luminal A, luminal B, triple-negative and HER-2-overexpression, according to the expression of ER, PR, HER-2 and Ki67. For each subtype, there were a total of 9, 87, 9 and 29 lesions, respectively. The clinical characteristics and pathological features of different molecular subtypes of breast cancer were evaluated. The present study was approved by the Ethics Committee of The Second Clinical College of Fujian Medical University and each patient involved in the study provided written informed consent.

Digital mammary gland three-dimensional tomosynthesis examination. Images captured by a digital mammary gland three-dimensional tomosynthesis system (Selenia Dimensions; Hologic, Inc., Marlborough, MA, USA) were analyzed for all patients. Craniocaudal position and mediolateral oblique (MLO) were observed. Each rotation of the $\mathrm{X}$-ray tube was limited within $15^{\circ}$, with a low-dose exposure once at a single $1^{\circ}$ rotation and a series of high-resolution computed tomography images were reconstructed by 15 frames. The full-field digital mammography and the DBT were obtained at the same stress position, also termed the COMBO mode.
Image post-processing. The securView 8.1 software (Hologic, Inc.) was used to post-process the acquired images, with the aim to display more gray shading and fine structure of the mammary gland, and improve the ability of image reading.

Evaluation methods. The selected 134 cases of breast cancer were classified according to the BI-RADS classification diagnosis criteria (21). During the process of classification, four physicians were involved to review the images, reaching a consensus for each patient.

Statistical analysis. SPSS software (version 20.0; IBM Corp., Armonk, NY, USA) was used for statistical analysis. Data with a normal distribution are presented as the mean \pm standard deviation. Data without a normal distribution are presented as the median (range). Numerical data of age was assessed for normal distribution with a Kolmogorov-Smirnov test followed by one-way analysis of variance and Fisher's Least Significant Difference test for pairwise comparisons within the group. Tumor size, calcification score and lymph node size were compared using a Kruskal-Wallis H test. All other indicators, including gland type, menopause, tumor margin, change in nipple position, change in peripheral glands, skin adhesion, thick blood vessels and lymphatic metastasis, and the thresholds of indicators, including tumor size, calcification score and lymph node size, were analyzed using a $\chi^{2}$ test or Fisher's exact test.

\section{Results}

Baseline characteristics of patients with different molecular subtypes of breast cancer. A total of 134 eligible patients were included in the present study. According to the expression of ER, PR, HER-2 and KI67, these patients were divided into four groups as follows: Luminal A subtype ( 9 cases with a age of $50.78 \pm 13.20$ years), luminal B subtype ( 87 cases with a age of $47.37 \pm 9.60$ years), triple-negative subtype (9 cases with a age of $47.00 \pm 8.32$ years) and HER-2-overexpression subtype (29 cases with a age of $51.45 \pm 9.64$ years). Four types of mammary glands were also included, including fat, few, mickle and dense. According to fat classification, the number of patients with the luminal B subtype was significantly higher compared with those with the luminal A subtype (Table I). Overall, no statistical differences were identified with regard to age, type of gland and menopause status in patients with different molecular subtypes of breast cancer $(\mathrm{P}<0.05$; Table I).

Comparative analysis of clinical data and pathological characteristic data in patients with different molecular subtypes of breast cancer. Indicators including tumor size, tumor margin (rough, partial or finishing), calcification score, change in nipple position (yes or no), change in peripheral glands (transition, invasion or obvious), skin adhesions (yes or no), thick blood vessels (yes or no), lymph node metastasis (yes or no) and lymph node size were determined using DBT. The results demonstrated that tumor size was larger in the triple-negative and HER-2-overexpression subtypes compared with in the luminal A and luminal B subtypes (Fig. 1). The tumor sizes in the luminal A, luminal B, triple-negative and HER-2-overexpression subtypes were $1.86 \pm 0.59,2.31 \pm 0.92$, 
Table I. General information of patients with different molecular subtypes of breast cancer.

\begin{tabular}{|c|c|c|c|c|c|}
\hline Characteristic & $\begin{array}{c}\text { Luminal A } \\
\text { subtype }(n=9)\end{array}$ & $\begin{array}{c}\text { Luminal B } \\
\text { subtype }(n=87)\end{array}$ & $\begin{array}{l}\text { Triple-negative } \\
\text { subtype }(n=9)\end{array}$ & $\begin{array}{l}\text { HER-2-overexpression } \\
\text { subtype }(\mathrm{n}=29)\end{array}$ & P-value \\
\hline Age, years (mean \pm standard deviation) & $50.78 \pm 13.20$ & $47.37 \pm 9.60$ & $47.00 \pm 8.32$ & $51.45 \pm 9.64$ & 0.219 \\
\hline \multirow[t]{5}{*}{ Mammary gland type, n (\%) } & & & & & 0.161 \\
\hline & $1(11.11)$ & $4(4.6)^{\mathrm{a}}$ & $0(0.00)$ & $3(10.34)$ & \\
\hline & $3(33.33)$ & $12(13.79)$ & $1(11.11)$ & $6(20.69)$ & \\
\hline & $2(22.22)$ & $63(72.41)$ & $7(77.78)$ & $18(62.07)$ & \\
\hline & $3(33.33)$ & $8(9.2)$ & $1(11.11)$ & $2(6.90)$ & \\
\hline \multicolumn{6}{|l|}{ Menopause, n (\%) } \\
\hline Yes & $4(44.44)$ & $30(34.48)$ & $3(33.33)$ & $1(48.15)$ & \\
\hline No & $5(55.56)$ & $57(65.52)$ & $6(66.67)$ & $14(51.85)$ & \\
\hline
\end{tabular}

${ }^{\mathrm{a}} \mathrm{P}<0.05$ vs. luminal A subtype. HER-2, human epidermal growth factor receptor 2 .

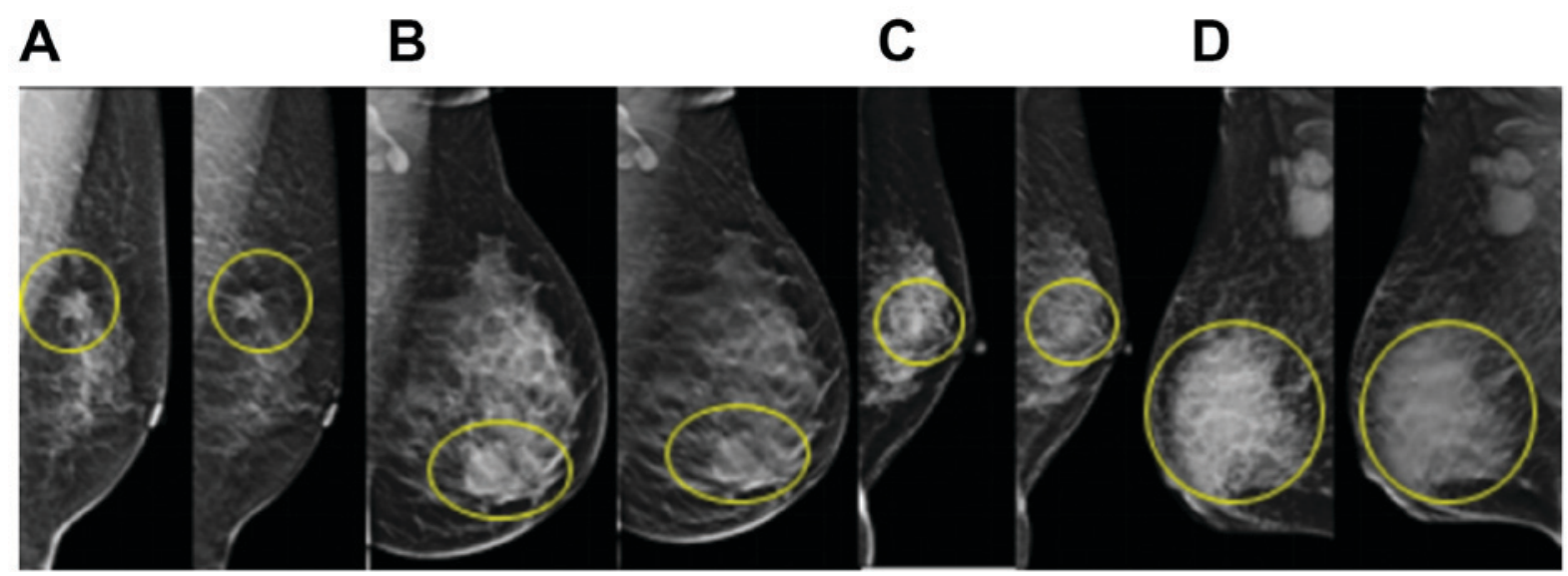

Figure 1. Tumors in different molecular subtypes of breast cancer. The yellow circles indicate the location of the lesion. (A) Luminal A subtype. Tumor size, $1.7 \times 1.5 \mathrm{~cm}$. (B) Luminal B subtype. Tumor size, $2.3 \mathrm{~cm}$. (C) Triple-negative subtype. Tumor size, $1.4 \times 1.0 \mathrm{~cm}$. (D) Human epidermal growth factor receptor 2-overexpression subtype. Tumor size, $7 \times 6 \mathrm{~cm}$. The left images in each panel were obtained from full-field digital mammography and the right images in each panel were obtained from digital breast three-dimensional tomosynthesis.

$3.74 \pm 1.94$ and $3.26 \pm 1.81$, respectively. However, statistical analysis revealed no significant differences between these four groups with regard to tumor size (Table II). The calcification score was significantly higher in the HER-2-overexpression subtype compared with in the luminal B subtype. Calcification scores for luminal A, luminal B, triple-negative and HER-2-overexpression subtypes were 9.57 $\pm 1.99,9.45 \pm 1.55$, $9.43 \pm 1.8$ and $11 \pm 1.41$, respectively. For the shape of tumor margin, no differences were revealed between the different molecular subtypes (Fig. 2). The change in peripheral glands included types of transition, invasion and no change. No significant differences were identified between the various subtypes with regard to change in peripheral glands, skin adhesion, change in nipple position and (Figs. 3 and 4; Table II).

In addition, the lymph node size for luminal $\mathrm{A}$, luminal B, triple-negative and HER-2-overexpression subtypes was $2.2 \pm 0.00,1.4 \pm 0.79,1.2 \pm 0.28$ and $2.01 \pm 0.59$, respectively. The lymph node size was significantly higher in the HER-2-overexpression subtype compared with in the luminal B subtype and the differences were statistically significant among the four groups $(\mathrm{P}<0.05$; Table II). But no significant differences were found between these four groups in tumor size. In summary, calcification score and lymph node size were revealed to be significantly different in the four molecular subtypes of breast cancer (Table II).

Subgroup analysis. To further analyze the clinical value of indices determined by DBT for the diagnosis of breast cancer molecular subtypes, the thresholds of indicators including tumor size, calcification score and lymph node size were calculated. According to the sixth edition of the breast cancer Tumor-Node-Metastasis staging system published by the American Joint Committee on Cancer (22), T1 stage tumors exhibit a maximum diameter $\leq 2 \mathrm{~cm}$ and tumor size is associated with prognosis, therefore $2 \mathrm{~cm}$ was selected in the present study as a cut-off value for tumor size. Lu et al (23) reported that a calcification score of 9 to 12 points indicates malignant calcification, therefore 10 points was selected as the cut-off value for calcification score in the present study. The incidence rate of $\geq 1.5 \mathrm{~cm}$ lymph node size has been identified to be significantly different from that of $\leq 1.5 \mathrm{~cm}$ lymph node size, which was significantly different from that of $0.6-1.4 \mathrm{~cm}$ 
Table II. Clinical and pathological features of different molecular subtypes of breast cancer.

\begin{tabular}{|c|c|c|c|c|c|}
\hline Characteristic & $\begin{array}{l}\text { Luminal A } \\
\text { subtype }\end{array}$ & $\begin{array}{c}\text { Luminal B } \\
\text { subtype }\end{array}$ & $\begin{array}{c}\text { Triple-negative } \\
\text { subtype }\end{array}$ & $\begin{array}{l}\text { HER-2-overexpression } \\
\text { subtype }\end{array}$ & P-value \\
\hline Tumor size, $\mathrm{cm}($ mean $\pm \mathrm{SD})$ & $1.86 \pm 0.59$ & $2.31 \pm 0.92$ & $3.74 \pm 1.94$ & $3.26 \pm 1.81$ & $\begin{array}{l}0.035,1.000^{\mathrm{a}}, 0.199^{\mathrm{b}}, \\
0.341^{\mathrm{c}}, 0.282^{\mathrm{d}}, 0.310^{\mathrm{e}}, \\
1.000^{\mathrm{f}}\end{array}$ \\
\hline Tumor margin, $\mathrm{n}(\%)$ & & & & & 0.093 \\
\hline Coarse & $4(80.00)$ & $46(63.01)$ & $3(42.86)$ & $10(50.00)$ & \\
\hline Partial & $0(0.00)$ & $24(32.88)$ & $4(57.14)$ & $6(30.00)$ & \\
\hline Finishing & $1(20.00)$ & $3(4.11)$ & $0(0.00)$ & $4(20.00)$ & \\
\hline Calcification score (mean \pm SD) & $9.57 \pm 1.99$ & $9.45 \pm 1.55$ & $9.43 \pm 1.81$ & $11 \pm 1.41$ & $\begin{array}{l}0.003,1.000^{\mathrm{a}}, 1.000^{\mathrm{b}}, \\
0.273^{\mathrm{c}}, 1.000^{\mathrm{d}}, 0.002^{\mathrm{e}}, \\
0.157^{\mathrm{f}}\end{array}$ \\
\hline Change in nipple position, $\mathrm{n}(\%)$ & & & & & 0.266 \\
\hline Yes & $1(11.11)$ & $9(10.34)$ & $2(22.22)$ & $7(24.14)$ & \\
\hline No & $8(88.89)$ & $78(89.66)$ & $7(77.78)$ & $22(75.86)$ & \\
\hline \multicolumn{6}{|l|}{ Change in peripheral glands, $\mathrm{n}(\%)$} \\
\hline Transition & $1(11.11)$ & $5(6.17)$ & $2(22.22)$ & $3(10.34)$ & \\
\hline Invasion & $5(55.56)$ & $4(54.2)$ & $5(55.56)$ & $16(55.17)$ & \\
\hline Unobvious & $3(33.33)$ & $35(40.23)$ & $2(22.22)$ & $10(34.48)$ & \\
\hline Skin adhesion, $\mathrm{n}(\%)$ & & & & & 0.389 \\
\hline Yes & $2(22.22)$ & $22(25.29)$ & $3(33.33)$ & $12(41.38)$ & \\
\hline No & $7(77.78)$ & $65(74.71)$ & $6(66.67)$ & $17(58.62)$ & \\
\hline Thick blood vessels, $\mathrm{n}(\%)$ & & & & & 0.978 \\
\hline Yes & $5(55.56)$ & $49(56.32)$ & $5(55.56)$ & $15(51.72)$ & \\
\hline No & $4(44.44)$ & $38(43.68)$ & $4(44.44)$ & $14(48.28)$ & \\
\hline Lymphatic metastasis, n (\%) & & & & & 0.435 \\
\hline Yes & $1(11.11)$ & $31(35.63)$ & $2(22.22)$ & $10(34.48)$ & \\
\hline No & $8(88.89)$ & $56(64.37)$ & $7(77.78)$ & $19(65.52)$ & \\
\hline Lymph node size, $\mathrm{cm}($ mean $\pm \mathrm{SD})$ & $2.2 \pm 0.00$ & $1.4 \pm 0.79$ & $1.2 \pm 0.28$ & $2.01 \pm 0.59$ & $\begin{array}{l}0.001,0.982^{\mathrm{a}}, 1.000^{\mathrm{b}}, \\
1.000^{\mathrm{c}}, 1.000^{\mathrm{d}}, 0.006^{\mathrm{e}}, \\
0.387^{\mathrm{f}}\end{array}$ \\
\hline
\end{tabular}

${ }^{a}$ Luminal A subtype vs. luminal B subtype. ${ }^{b}$ Luminal A subtype vs. triple-negative subtype. ${ }^{c}$ Luminal A subtype vs. HER-2-overexpression subtype. ${ }^{~}$ Luminal B subtype vs. triple-negative subtype. ${ }^{\mathrm{e}}$ Luminal B subtype vs. HER-2-overexpression subtype. ${ }^{\mathrm{f}}$ Triple-negative subtype vs. HER-2-overexpression subtype. HER-2, human epidermal growth factor receptor 2; SD, standard deviation.

lymph node size (24). Therefore, $15 \mathrm{~mm}$ was selected as the cut-off value for lymph node size in the present study. The analysis demonstrated that lymph node size and calcification score exhibited statistically significant differences among the four groups $(\mathrm{P}<0.05$; Table III).

\section{Discussion}

Breast cancer is a clinically heterogeneous disease with a varied clinical profile. The results of the present study highlighted that diagnostic imaging features, including calcification score and lymph node size, determined using DBT may be used as assistant diagnostic markers of breast cancer molecular subtypes. Existing histological classifications may not be fully consistent with the clinical behavior of this disease (25). ER, PR, HER-2, EGFR and basal marker expression status indicates the molecular subtype of breast cancer, and may predict or influence the prognosis and response to hormonal and targeted therapies (5). However, there are a lack of non-invasive methods for the molecular classification of breast cancer. On the basis of a previous study that indicated that the sensitivity of breast cancer diagnosis increases from $60 \%$ using traditional digital mammography to $82.9 \%$ using DBT (16), the present study investigated further the associations between breast cancer molecular subtypes and DBT imaging characteristics, including tumor margin, surrounding bright ring of tumor, vascular images and calcification foci, lymph node size and associations with surrounding glandular tissue. The aim of the present study was to demonstrate that DBT may serve as a clinical diagnostic tool for diagnosing molecular subtypes of breast cancer. 


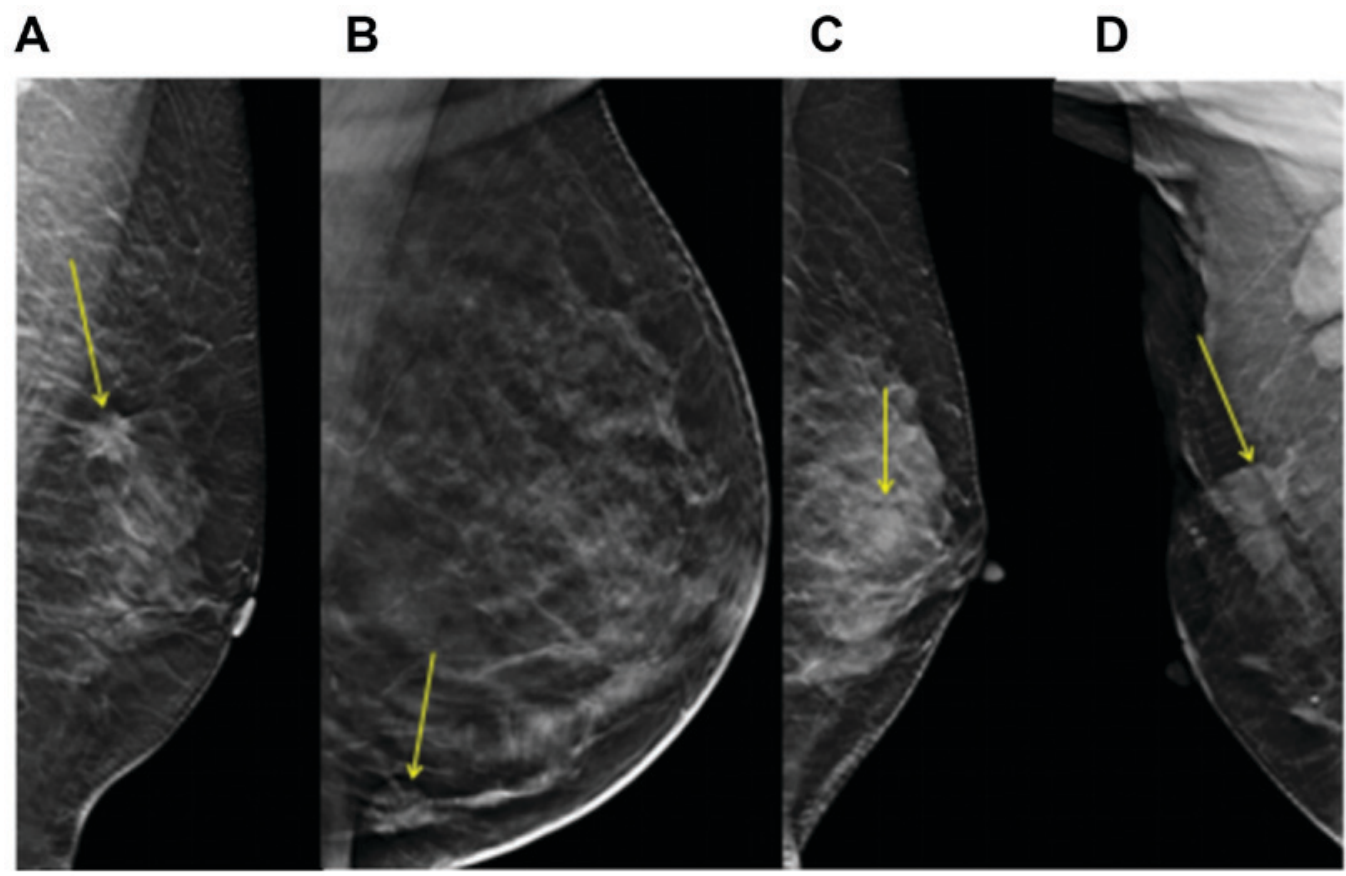

Figure 2. Tumor margin type of different molecular subtypes of breast cancer. The yellow arrows indicate the location of the lesions. (A) Luminal A subtype. (B) Luminal B subtype. (C) Triple-negative subtype. (D) Human epidermal growth factor receptor 2-overexpression subtype.
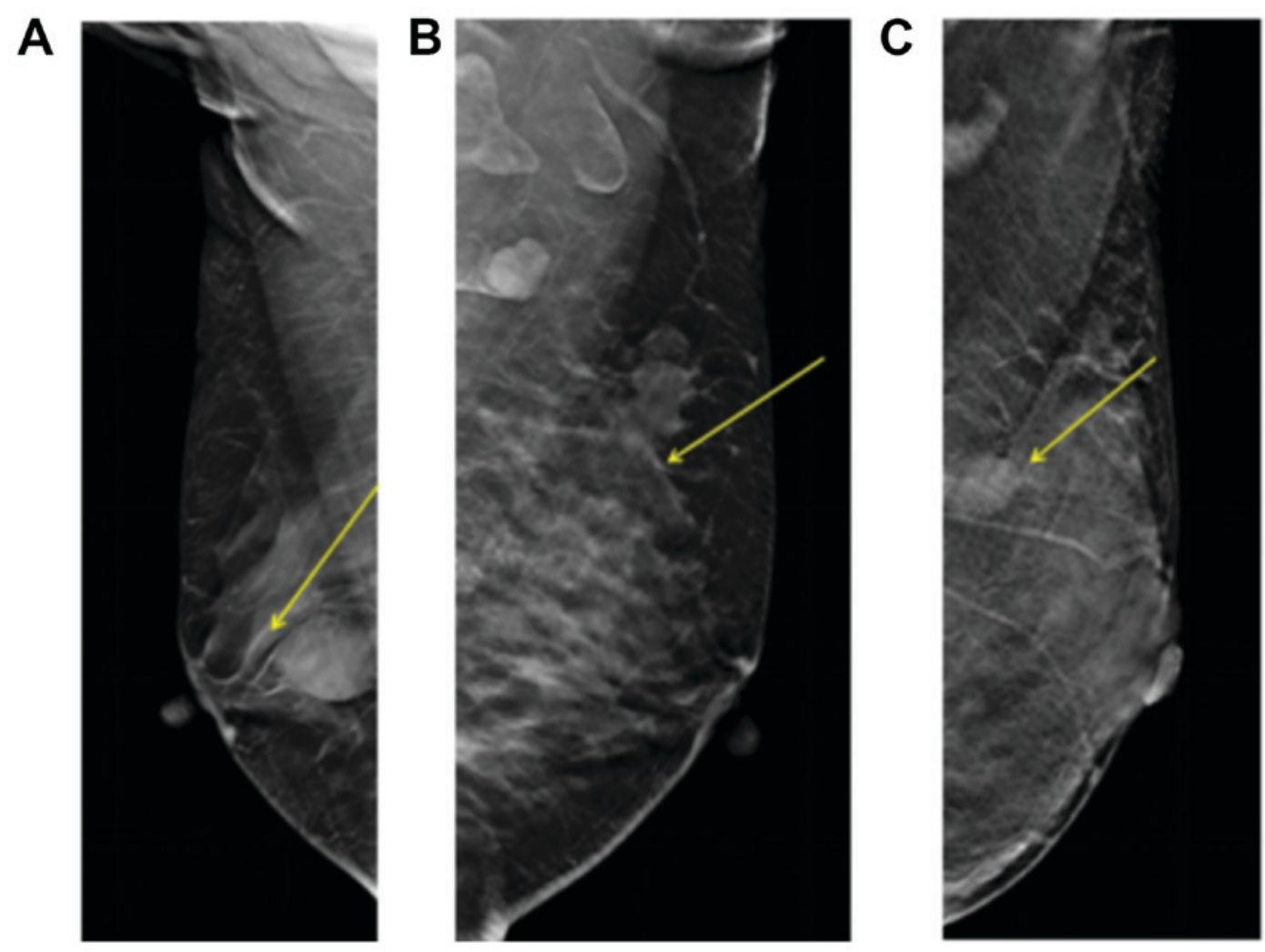

Figure 3. Change in peripheral glands. The yellow arrows indicate the location of the lesions. (A) Peripheral gland transition. (B) Peripheral gland invasion. (C) Peripheral glands without obvious change.

Immunohistochemistry may be used easily and widely to classify molecular subtypes of breast tumors, and these subtypes have been demonstrated to exhibit significant differences regarding tumor size, histological grade, lymph node positivity and lymphovascular emboli, which is important for treatment planning and targeted therapy $(26,27)$. In the present study, calcification score and lymph node size were identified as indicators with significant differences when compared between the four molecular subtypes of breast cancer. Subgroup analysis based on tumor size, calcification score and lymph node size 
Table III. Cut-off values of tumor size, calcification score and lymph node size measured by digital breast three-dimensional tomosynthesis for diagnosing breast cancer molecular subtypes.

\begin{tabular}{|c|c|c|c|c|c|c|}
\hline Characteristic & $\begin{array}{l}\text { Luminal A } \\
\text { subtype }\end{array}$ & $\begin{array}{c}\text { Luminal B } \\
\text { subtype }\end{array}$ & $\begin{array}{l}\text { Triple- } \\
\text { negative } \\
\text { subtype }\end{array}$ & $\begin{array}{l}\text { HER-2- } \\
\text { overexpression } \\
\text { subtype }\end{array}$ & $\chi^{2}$ & P-value \\
\hline Tumor size, cm & & & & & 1.82 & 0.610 \\
\hline$<2$ & $3(60.00)$ & $28(38.36)$ & $2(28.57)$ & $6(30.00)$ & & \\
\hline$\geq 2$ & $2(40.00)$ & 45 (61.64) & $5(71.43)$ & $14(70.00)$ & & \\
\hline Calcification score & & & & & 13.31 & $\begin{array}{l}0.002,1.000^{\mathrm{a}}, 1.000^{\mathrm{b}}, \\
0.038^{\mathrm{c}}, 1.000^{\mathrm{d}},<0.001^{\mathrm{e}}, \\
0.038^{\mathrm{f}}\end{array}$ \\
\hline$<10$ & $4(57.14)$ & $36(56.25)$ & $4(57.14)$ & $3(13.64)$ & & \\
\hline$\geq 10$ & $3(42.86)$ & $28(43.75)$ & $3(42.86)$ & $19(86.36)$ & & \\
\hline Lymph node size, $\mathrm{cm}$ & & & & & 14.12 & $\begin{array}{l}<0.001,0.300^{\mathrm{a}}, \\
0.333^{\mathrm{b}}, 1.000^{\mathrm{c}}, 1.000^{\mathrm{d}}, \\
0.001^{\mathrm{e}}, 0.045^{\mathrm{f}}\end{array}$ \\
\hline$<1.5$ & $0(0.00)$ & $21(72.41)$ & $2(100.00)$ & $1(10.00)$ & & \\
\hline$\geq 1.5$ & $1(100.00)$ & $8(27.59)$ & $0(0.00)$ & $9(90.00)$ & & \\
\hline
\end{tabular}

Data are presented as n (\%). ${ }^{\mathrm{a}}$ Luminal A subtype vs. luminal B subtype. ${ }^{\mathrm{b}}$ Luminal A subtype vs. triple-negative subtype. ${ }^{\circ}$ Luminal A subtype vs. HER-2-overexpression subtype. ${ }^{\mathrm{d}}$ Luminal B subtype vs. triple-negative subtype. ${ }^{\mathrm{e}}$ Luminal B subtype vs. HER-2-overexpression subtype. ${ }^{\mathrm{f}}$ Triple-negative subtype vs. HER-2-overexpression subtype. HER-2, human epidermal growth factor receptor 2.
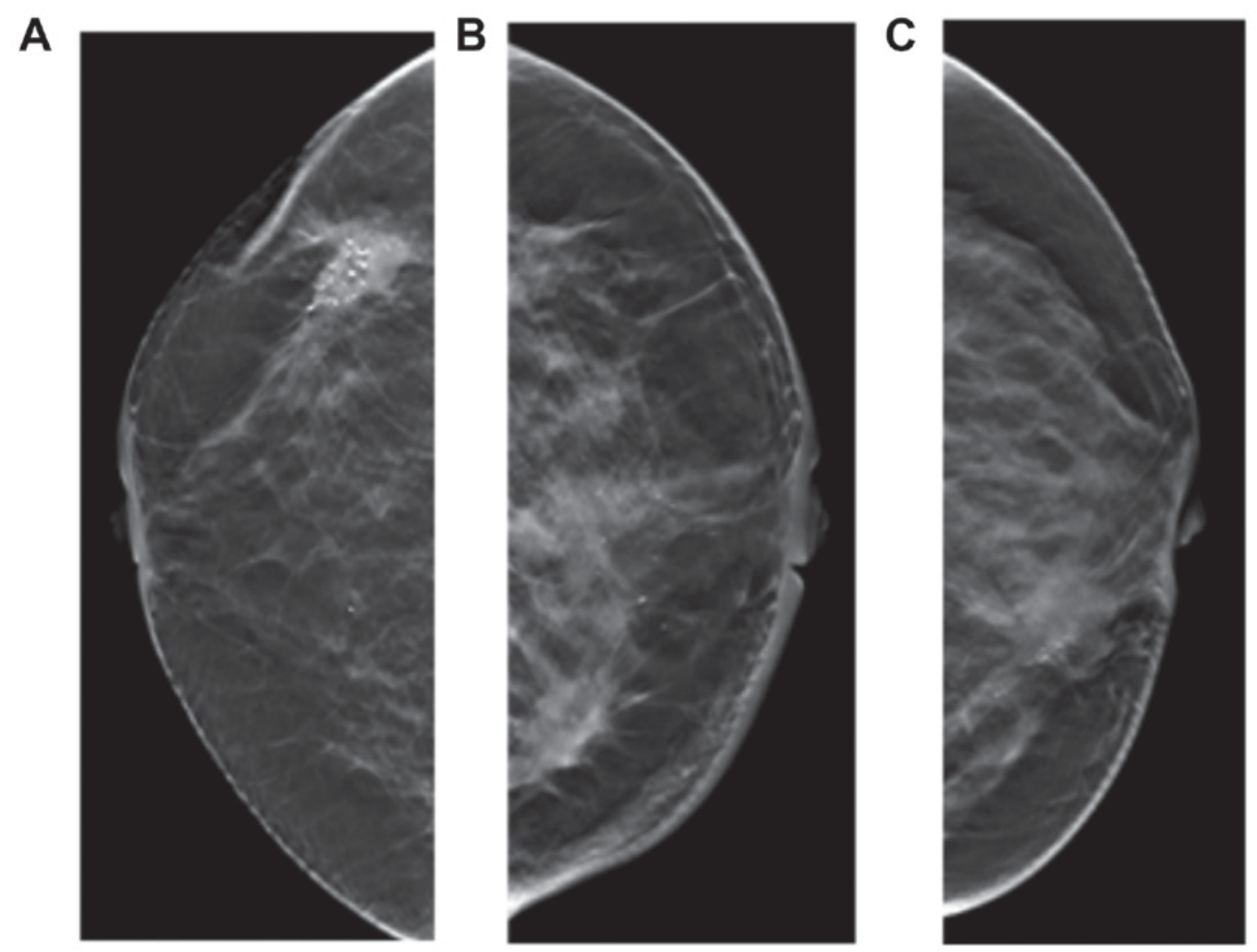

Figure 4. Signs of skin adhesion, nipple retraction and thick blood vessels. (A) Skin adhesion. (B) Nipple retraction. (C) Thick blood vessels.

revealed significant differences in the distribution of patients with calcification scores $\geq 10$ and $<10$, and lymph node size $\geq 1.5$ and $<1.5 \mathrm{~cm}$; however, no significant differences were identified for tumor size $\geq 2$ and $<2 \mathrm{~cm}$. In addition, DBT effectively detected the tumor margin, surrounding bright ring of tumor, vascular images and calcification foci, lymph node 
size and associations with surrounding glandular tissue, which indicates that DBT may be used as a diagnostic tool for the determination of breast cancer molecular subtypes.

The present study identified that patients with HER-2-overexpression subtype exhibited a larger tumor size and higher calcification score compared with Luminal B subtype. Additionally, the calcification score was significantly associated with molecular subtypes of breast cancer. This was in accordance with a number of previous studies, which have identified an association between HER-2 expression and calcification. Yang and Tse (28) reported that the calcification rates of triple-negative, HER-2-positive and ER-positive breast cancer, identified by breast X-ray photography examination, were 15,67 and $61 \%$, respectively, which indicates that the calcification rate is higher in patients with ER and HER-2 expression. Ko et al (29) revealed that tumor mass or partial structural asymmetry, and not fine calcification, were the most common signs in patients with triple-negative breast cancer during X-ray examination. In addition, Kim et al (30) identified that the presence of calcification was significantly higher in patients with an ER-negative subtype of breast cancer compared with patients with HER-2 expression. The results of the present study identified that the highest calcification score was associated with HER-2-overexpressed breast cancer, which suggests that evaluation of calcification score may be used to predict molecular subtypes and prognosis. Notably, a threshold analysis of calcification score was performed in the present study and statistically significant differences were revealed among the four groups when the threshold of calcification score was 10 points.

Furthermore, the present study identified that lymph node size for the four molecular subtypes of breast cancer was significantly different and lymph node size was significantly associated with molecular subtypes. Statistically significant differences between different subtypes were revealed when the threshold of lymph node size was $1.5 \mathrm{~cm}$. When certain cases could not be observed through the MLO view, lymph nodes were also observed by magnification mammography (data not shown); however, the lymph node could generally only be observed by MLO view. It has been suggested that the ratio of metastatic to dissected lymph nodes, termed the lymph node ratio (LNR), can be used as a superior prognostic factor with a high sensitivity for evaluating lymph nodes (31). In a previous study, among 640 early breast cancer cases, data collected from 469 cases with axillary lymph node metastasis were retrospectively analyzed (31). The LNR in luminal A, luminal B HER-2+, HER-2-overexpression and basal-like subtypes was 35.2, 43.2, 46.9 and $39.1 \%$, respectively. A significant difference was identified between subtypes luminal A and HER-2-overexpression $(\mathrm{P}=0.023)$. LNR was significantly associated with tumor size and lymphovascular invasion; however, no significant association was observed for other prognostic factors, including menopausal status, laterality, grade and perineural invasion. When the cut-off value was defined as $29.8 \%$ for LNR, significant differences in survival rates were identified between basal-like type and both luminal A $(\mathrm{P}=0.003)$ and luminal B HER-2 ${ }^{+}(\mathrm{P}=0.04)$ subtypes. In summary, the LNR was different in certain molecular subtypes of breast cancer and was associated with prognostic indicators and survival. These results support the use of LNR to evaluate breast cancer (31). In the present study, the imaging characteristics detected by DBT, including tumor margin, surrounding bright ring of tumor, vascular images and associations with surrounding glandular tissue were not markedly different in different molecular subtypes of breast cancer.

The present study was retrospective with a limited sample size, therefore the individuals in each subtype were not particularly uniform. Future studies should increase the sample size and perform receiver operator characteristic analysis to calculate the sensitivity and specificity of each indicator. In addition, this may detect more characteristics associated with different molecular subtypes, which may promote pre-operative clinical judgment and personalized treatment strategies. Furthermore, calcifications are a common sign of invasive ductal carcinoma with ductal carcinoma in situ, therefore future studies may focus on the associations between imaging features of DBT and pathological subtypes of breast cancer.

In conclusion, the results of the present study suggest that diagnostic imaging features determined using DBT, including calcification score and lymph node size, are significantly associated with molecular subtypes of breast cancer and may be used as assistant diagnostic markers of molecular subtypes of breast cancer.

\section{Acknowledgments}

Not applicable.

\section{Funding}

Not applicable.

\section{Availability of data and materials}

The datasets used and/or analyzed during the current study are available from the corresponding author on reasonable request.

\section{Authors' contributions}

SC designed the study. MY performed data analysis, drafted the manuscript and revised the manuscript. DC, JY, MH, LY and $\mathrm{HH}$ made contributions to data acquisition, analysis and interpretation.

\section{Ethics approval and consent to participate}

The present study was approved by the Ethics Committee of The Second Clinical College of Fujian Medical University and each patient involved in the study provided written informed consent.

\section{Patient consent for publication}

Patients provided written informed consent for the publication of their data.

\section{Competing interests}

The authors declare that they have no competing interests. 


\section{References}

1. Hortobagyi GN, de la Garza Salazar J, Pritchard K, Amadori D, Haidinger R, Hudis CA, Khaled H, Liu MC, Martin M, Namer M, et al: The global breast cancer burden: Variations in epidemiology and survival. Clin Breast Cancer 6: 391-401, 2005.

2. Tao Z, Shi A, Lu C, Song T, Zhang Z and Zhao J: Breast cancer: Epidemiology and etiology. Cell Biochem Biophys 72: 333-338, 2015.

3. Perou CM, Sørlie T, Eisen MB, van de Rijn M, Jeffrey SS, Rees CA, Pollack JR, Ross DT, Johnsen H, Akslen LA, et al: Molecular portraits of human breast tumours. Nature 406: 747-752, 2000

4. Sørlie T, Perou CM, Tibshirani R, Aas T, Geisler S, Johnsen H, Hastie T, Eisen MB, van de Rijn M, Jeffrey SS, et al: Gene expression patterns of breast carcinomas distinguish tumor subclasses with clinical implications. Proc Natl Acad Sci USA 98: 10869-10874, 2001.

5. Carey LA, Perou CM, Livasy CA, Dressler LG, Cowan D, Conway K, Karaca G, Troester MA, Tse CK, Edmiston S, et al: Race, breast cancer subtypes, and survival in the Carolina breast cancer study. JAMA 295: 2492-2502, 2006.

6. Li X, Huang Y, Shuqin Z, Chen Z and Zhang S: Re: Association between imaging characteristics and different molecular subtypes of breast cancer. Acad Radiol 24: 1184, 2017.

7. Eroles P, Bosch A, Pérez-Fidalgo JA and Lluch A: Molecular biology in breast cancer: Intrinsic subtypes and signaling pathways. Cancer Treat Rev 38: 698-707, 2012.

8. Liedtke C and Kiesel L: Breast cancer molecular subtypes-modern therapeutic concepts for targeted therapy of a heterogeneous entity. Maturitas 73: 288-294, 2012.

9. Di Gioia D, Stieber P, Schmidt GP, Nagel D, Heinemann V and Baur-Melnyk A: Early detection of metastatic disease in asymptomatic breast cancer patients with whole-body imaging and defined tumour marker increase. Br J Cancer 112: 809-818, 2015.

10. Zelig U, Barlev E, Bar O, Gross I, Flomen F, Mordechai S, Kapelushnik J, Nathan I, Kashtan H, Wasserberg N and Madhala-Givon O: Early detection of breast cancer using total biochemical analysis of peripheral blood components: A preliminary study. BMC Cancer 15: 408, 2015.

11. Rao M, Stough J, Chi YY, Muller K, Tracton G, Pizer SM and Chaney EL: Comparison of human and automatic segmentations of kidneys from CT images. Int J Radiat Oncol Biol Phys 61: 954-960, 2005

12. Takamoto Y, Tsunoda H, Kikuchi M, Hayashi N, Honda S, Koyama T, Ohde S, Yagata H, Yoshida A and Yamauchi $\mathrm{H}$ : Role of breast tomosynthesis in diagnosis of breast cancer for Japanese women. Asian Pac J Cancer Prev 14: 3037-3040, 2013.

13. Roth RG, Maidment AD, Weinstein SP, Roth SO and Conant EF: Digital breast tomosynthesis: Lessons learned from early clinical implementation. Radiographics 34: E89-E102, 2014.

14. Tang W, Li R, Gao Y, Wang Q, Shen Q, Gu Y and Peng W: A comparative study of diagnostic performance between digital breast tomosynthesis and conventional imaging methods. China Oncol 27: 487-495, 2017.

15. Mariscotti G, Houssami N, Durando M, Campanino PP, Regini E, Fornari A, Bussone R, Castellano I, Sapino A, Fonio P and Gandini G: Digital breast tomosynthesis (DBT) to characterize MRI-detected additional lesions unidentified at targeted ultrasound in newly diagnosed breast cancer patients. Eur Radiol 25: 2673-2681, 2015.

16. Cai SQ, Yan JX, Chen QS, Huang ML and Cai DL: Significance and application of digital breast tomosynthesis for the BI-RADS classification of breast cancer. Asian Pac J Cancer Prev 16: 4109-4114, 2015.
17. Wiechmann L, Sampson M, Stempel M, Jacks LM, Patil SM, King $\mathrm{T}$ and Morrow M: Presenting features of breast cancer differ by molecular subtype. Ann Surg Oncol 16: 2705-2710, 2009.

18. Cen D, Xu L, Li N, Chen Z, Wang L, Zhou S, Xu B, Liu Cl, Liu Z and Luo T: BI-RADS 3-5 microcalcifications can preoperatively predict breast cancer HER2 and Luminal a molecular subtype. Oncotarget 8: 13855-13862, 2017.

19. Pan B, Yao R, Zhou YD, Zhu QL, Shi J, Xu QQ, Wang CJ, You SS, Mao F, Lin Y, et al: Tumor biology, clinicopathological characteristics and prognosis of screen detected T1 invasive non-palpable breast cancer in asymptomatic Chinese women (2001-2014). Oncotarget 8: 26221-26230, 2017.

20. Partyka L, Lourenco AP and Mainiero MB: Detection of mammographically occult architectural distortion on digital breast tomosynthesis screening: Initial clinical experience. AJR Am J Roentgenol 203: 216-222, 2014.

21. Sickles EA, D'Orsi CJ, Bassett LW, et al: ACR BI-RADS ${ }^{\circledR}$ Mammography. In: ACR BI-RADS ${ }^{\circledR}$ Atlas, Breast Imaging Report and Date System. American College of Radiology, Reston, VA, 15-75, 2013.

22. Wang W, Bai YH, Deng YM, et al: Stsage-specific Survival Analysis according to the 2002 American Joint Committee on breast cancer staging system. Pract J Cancer 22: 286-289, 2007 (in Chinese).

23. Lu J, Ni C and Wu D: Breast benign and malignant calcification score and clinical application. Chin J Med Imaging: 385-387, 2008.

24. Shaolin L, Jun L, Licong F, Peikun Z and Han L: Correlation between size and metastasis of mediastinal lymph nodes in lung cancer by CT examination. Qilu Tumor J 75, 1998.

25. Goldhirsch A, Winer EP, Coates AS, Gelber RD, Piccart-Gebhart M, Thürlimann B and Senn HJ; Panel Members: Personalizing the treatment of women with early breast cancer: Highlights of the St gallen international expert consensus on the primary therapy of early breast cancer 2013. Ann Oncol 24: 2206-2223 2013

26. Kumar N, Patni P, Agarwal A, Khan MA and Parashar N: Prevalence of molecular subtypes of invasive breast cancer: A retrospective study. Med J Armed Forces India 71: 254-258, 2015.

27. Bennis S, Abbass F, Akasbi Y, Znati K, Joutei KA, El Mesbahi O and Amarti A: Prevalence of molecular subtypes and prognosis of invasive breast cancer in north-east of Morocco: Retrospective study. BMC Res Notes 5: 436, 2012.

28. Yang WT and Tse GM: Sonographic, mammographic, and histopathologic correlation of symptomatic ductal carcinoma in situ. AJR Am J Roentgenol 182: 101-110, 2004.

29. Ko ES, Lee BH, Kim HA, Noh WC, Kim MS and Lee SA: Triple-negative breast cancer: Correlation between imaging and pathological findings. Eur Radiol 20: 1111-1117, 2010.

30. Kim SH, Seo BK, Lee J, Kim SJ, Cho KR, Lee KY, Je BK, Kim HY, Kim YS and Lee JH: Correlation of ultrasound findings with histology, tumor grade, and biological markers in breast cancer. Acta Oncol 47: 1531-1538, 2008

31. Demircioglu F, Demirci U, Kilic D, Ozkan S and Karahacioglu E: Clinical significance of lymph node ratio in locally advanced breast cancer molecular subtypes. Onkologie 36: 637-640, 2013.

(i) (2) This work is licensed under a Creative Commons Attribution-NonCommercial-NoDerivatives 4.0 International (CC BY-NC-ND 4.0) License. 